\title{
Kemandirian Keluarga Berencana (KB) pada Pasangan Usia Subur di Kota Yogyakarta
}

\author{
Susiana Sariyati ${ }^{1}$, Sundari Mulyaningsih ${ }^{2}$, Hamam Hadi ${ }^{3}$ \\ 1, 2, 3 Sekolah Tinggi IImu Kesehatan Alma Ata Yogyakarta \\ Jalan Ringroad Barat Daya No 1 Tamantirto, Kasihan, Bantul Yogyakarta
}

\begin{abstract}
Abstrak
Keluarga Berencana sebagai kebutuhan masyarakat dan saat ini perannya mulai di berikan kepada masyarakat secara mandiri. Kondisi inilah dimanfaatkan BKKBN untuk lebih memacu ke arah kemandirian.

Provinsi Daerah Istimewa Yogyakarta (DIY) sebagai salah satu provinsi di Indonesia yang mempunyai peserta KB aktif cukup tinggi. Pada tahun 2012 peserta KB aktif mencapai 34.373 (73,29\%) dari 47.339 pasangan usia subur (BKKBN 2012). Tujuan penelitian ini untuk mengetahui gambaran kemandirian KB pada pasangan usia subur (PUS) di Kota Yogyakarta tahun 2013. Jenis penelitian ini adalah deskriptif dengan metode pendekatan survey deskriptif. Populasi dalam penelitian ini adalah peserta KB aktif dengan besar sampel sebanyak 521. Tehnik pengambilan sampel lokasi penelitian dilakukukan dengan cara Probability Proportional to Size (PPS), sedangkan penentuan responden dengan tehnik random sampling. Analisis data dilakukan dengan analisis univariat. Dalam penelitian ini didapatkan paling banyak pasangan usia subur yang memperoleh alat kontrasepsi dengan membayar penuh dan memiliki jaminan kesehatan sebanyak 143 (52,2\%) dengan alasan kemandirian KB adalah faktor ekonomi yang mendukung sebanyak 128 responden (46,7\%). Simpulan kemandirian KB di Kota Yogyakarta dapat digambarkan bahwa sebagian besar layanan KB dilakukan dengan membayar penuh karena mayoritas memiliki kartu jaminan kesehatan.
\end{abstract}

Kata Kunci: Kemandirian, Keluarga Berencana, Pasangan Usia Subur

\section{Independency Family Planning (KB) of Fertile Age Couples in Yogyakarta}

\begin{abstract}
Family planning is part of the needs of the community, todays, by the government has given to the community. This condition was used by BKKBN as a trigger to improve toward independence. Yogyakarta Province (DIY) as the one province in Indonesia which has high number of active acceptors. In 2012, active acceptors has reached 34.373 (73.29\%) of 47339 couples of productive age (BKKBN 2012). This research aimed to know representation of KB independence in couples of childbearing age (EFA) in Yogyakarta 2013. This is a descriptive research with descriptive survey approach. The population of study was an active family planning participants with a sample size of 521. Sampling techniques was done by Probability Proportional to Size (PPS), while respondents were determined with random sampling technique. Data was analyzed using univariate analysis. In this study, contraception was widely obtained by couple of childbearing age with fully paying and health insurance total of $143(52.2 \%)$ with the reason of having KB independence was because of economic factors at 128 respondents (46.7\%). In conclusion, Independence KB in Yogyakarta can be represented that mostly $K B$ is provided through paying full as the majority have a health insurance.
\end{abstract}

Keywords: Independency, Family Planning, Couple Eligible

Info Artikel:

Artikel dikirim pada 10 Januari 2014

Artikel diterima pada 10 Januari 2014 


\section{Pendahuluan}

Rencana Strategis Program Kependudukan dan KB tahun 2010-2014 diarahkan untuk meningkatkan akuntabilitas pelaksanaan Pengendalian Kependudukan dan Program Keluarga Berencana dalam mendukung terwujudnya Visi yaitu Penduduk Tumbuh Seimbang 2015 dan Misi Mewujudkan Pembangunan Berwawasan Kependudukan dan Keluarga Kecil Bahagia Sejahtera ${ }^{1}$.

Pelayanan keluarga berencana juga ditujukan untuk mendukung pencapaian target Millenium Development Goal (MDG's) terutama point 5b mengenai Angka Kematian Ibu (AKI) melalui peningkatan kualitas dan cakupan sasaran pelayanan keluarga.

Program Keluarga Berencana Nasional mempunyai kontribusi penting dalam upaya meningkatkan kualitas penduduk. Salah satu upaya untuk menangani jumlah penduduk adalah melalui kontrol terhadap faktor-faktor yang mempengaruhi laju utama penduduk. Salah satu cara yang ditempuh untuk menekan laju pertumbuhan penduduk adalah dengan melakukan Program Keluarga Berencana untuk mengendalikan fertilitas. Terjadinya kenaikan Total Fertility Rate (TFR) disebabkan oleh beberapa faktor diantaranya masih banyak Pasangan Usia Subur yang tidak ber KB, laju pertumbuhan penduduk yang tinggi dan tingginya unmet need.

Angka pemakaian kontrasepsi, contraceptive prevalance rate (CPR) mengalami peningkatan dari $60,3 \%$ pada tahun 2003 menjadi $61,4 \%$ pada tahun 2007. Pada tahun 2015 jumlah penduduk Indonesia hanya mencapai 255,5 juta jiwa, namun jika terjadi penurunan CPR $1 \%$ saja, jumlah penduduk mencapai 264,4 juta jiwa atau lebih. Apabila pelayanan KB dapat meningkatkan CPR sebesar $1 \%$ maka penduduk di Indonesia yaitu 237,8 juta jiwa².

Provinsi Daerah IstimewaYogyakarta (DIY) merupakan salah satu provinsi di Indonesia yang mempunyai peserta KB aktif cukup tinggi. Pada tahun 2012 peserta KB aktif mencapai 34.373 (73,29\%) dari 47.339 pasangan usia subur ${ }^{3}$. Penelitian ini bertujuan untuk mengetahui Gambaran Kemandirian KB Pada Pasangan Usia Subur di Kota Yogyakarta tahun 2013.

\section{Bahan dan Metode}

Jenis penelitian ini adalah deskriptif dengan rancangan penelitian survei deskriptif. Populasi dalam penelitian ini adalah Semua pasangan usia subur di Kota Yogyakarta yang berumur 15-49 tahun dengan sampel adalah peserta KB aktif sampel 521 orang. Cara pengambilan sampel dengan cara teknik Probability Proportional to Size (PPS) sedangkan penentuan responden dengan tehnik random sampling. Analisis data dilakukan dengan analisis univariat yang diambil dari 30 RW dalam 30 kelurahan.

\section{Hasil dan Pembahasan}

Tabel 1. Distribusi Frekuensi Berdasarkan Karakteristik Peserta KB Aktif di Kota Yogyakarta tahun 2013.

\begin{tabular}{|c|c|c|}
\hline Karakteristik & Frekuensi & $\%$ \\
\hline \multicolumn{3}{|l|}{ Umur Istri } \\
\hline$<20$ tahun & 8 & 1,5 \\
\hline $20-35$ tahun & 215 & 41,3 \\
\hline$>35$ tahun & 298 & 57,2 \\
\hline Total & 521 & 100 \\
\hline \multicolumn{3}{|l|}{ Umur Suami } \\
\hline$<20$ tahun & 1 & 0,1 \\
\hline $20-35$ tahun & 169 & 32,4 \\
\hline$>35$ tahun & 351 & 67,3 \\
\hline Total & 521 & 100,0 \\
\hline \multicolumn{3}{|l|}{ Pendidikan Istri } \\
\hline Rendah (tidak tamat SD, tamat SD) & 36 & 5,8 \\
\hline Menengah (SMP dan SMA) & 389 & 74,0 \\
\hline Tinggi (Diploma/ lebih tinggi) & 96 & 19,2 \\
\hline Total & 521 & 100 \\
\hline \multicolumn{3}{|l|}{ Pendidikan Suami } \\
\hline Rendah (tidak tamat SD, tamat SD) & 36 & 5,8 \\
\hline Menengah (SMP dan SMA) & 389 & 74,0 \\
\hline Tinggi (Diploma/ lebih tinggi) & 96 & 19,2 \\
\hline Total & 521 & 100 \\
\hline \multicolumn{3}{|l|}{ Pekerjaan Istri } \\
\hline petani/peternak/nelayan & 0 & 0 \\
\hline Buruh/buruh Tani & 38 & 7,2 \\
\hline Karyawan Swasta & 55 & 10,6 \\
\hline Pegawai negri/ TNI /POLRI & 19 & 3,6 \\
\hline Wiraswasta & 109 & 20,9 \\
\hline Tidak bekerja (Ibu Rumah Tingga) & 282 & 54,1 \\
\hline lain-lain & 18 & 3,4 \\
\hline Total & 512 & 100,0 \\
\hline \multicolumn{3}{|l|}{ Pekerjaan Suami } \\
\hline petani/peternak/nelayan & 3 & 0,6 \\
\hline Buruh/buruh Tani & 101 & 19,4 \\
\hline Karyawan Swasta & 144 & 27,6 \\
\hline Pegawai negri/ TNI /POLRI & 35 & 6,7 \\
\hline Wiraswasta & 176 & 33,8 \\
\hline Tidak bekerja & 6 & 1,2 \\
\hline lain-lain & 56 & 10,7 \\
\hline Total & 521 & 100,0 \\
\hline
\end{tabular}

Sumber: Data Primer

Berdasarkan Tabel 1 menunjukan bahwa umur istri paling banyak yaitu pada umur lebih dari 35 tahun sejumlah 298 responden $(51,2 \%)$, Umur suami paling banyak pada umur lebih dari 35 tahun sejumlah 351 responden $(67,3 \%)$, Pendidikan istri paling banyak berpendidikan menengah sejumlah 358 responden (74\%), Pendidikan suami paling banyak berpendidikan menengah sejumlah 358 responden ( $74 \%$ ), Pekerjaan istri paling banyak tidak bekerja 
sejumlah 282 responden (54,1\%), Pekerjaan suami paling banyak bekerja sebagai wiraswasta sejumlah 176 responden $(33,8 \%)$.

Tabel 2. Distribusi Frekuensi Cara/Alat Memperoleh Kontrasepsi yang digunakan di Kota Yogyakarta Tahun 2013.

\begin{tabular}{lcc}
\hline Alat/Cara Memperoleh & Frekuensi & \% \\
\hline Gratis & 218 & 41.8 \\
Membayar Sebagian & 29 & 5.6 \\
Membayar Penuh & 274 & 52.6 \\
\hline Jumlah & 521 & 100.0 \\
\hline
\end{tabular}

Sumber: Data Primer 2013.

Berdasarkan Tabel 2 menunjukan bahwa akseptor KB aktif paling banyak memperoleh alat atau cara kontrasepsi dengan cara membayar penuh sejumlah 274 responden (52,6\%), sedangkan paling sedikit akseptor memilih alat cara atau kontrasepsi dengan cara membayar sebagian sejumlah 29 responden $(5,6 \%)$.

Tabel 3. Distribusi Frekuensi Kepemilikan Kartu Jaminan Kesehatan di Kota Yogyakarta Tahun 2013.

\begin{tabular}{lll}
\hline KepemilikanJaminan Kesehatan & Frekuensi & $\%$ \\
\hline Ya & 312 & 59.9 \\
Tidak & 209 & 40.1 \\
\hline Jumlah & 521 & 100.0 \\
\hline
\end{tabular}

Sumber : Data Primer 2013.

Berdasarkan Tabel 3 menunjukan bahwa kepemilikan kartu jaminan kesehatan pada akseptor KB aktif paling banyak memiliki kartu jaminan kesehatan sejumlah 312 responden (59,9\%) dan yang tidak memiliki kartu jaminan kesehatan sejumlah 209 responden $(40,1 \%)$.

Tabel 4. Tabulasi Silang Cara atau Alat Memperoleh Kontrasepsi yang digunakan dengan Kepemilikan Kartu Jaminan Kesehatan di Kota Yogyakarta tahun 2013

\begin{tabular}{lcccc}
\hline $\begin{array}{c}\text { Cara atau Alat } \\
\text { Kontrasepsi yang } \\
\text { digunakan }\end{array}$ & \multicolumn{2}{c}{$\begin{array}{c}\text { kepemilikan Kartu } \\
\text { Jamninan Kesehatan }\end{array}$} & \multirow{2}{*}{ Total } & $\%$ \\
\cline { 2 - 3 } & 154 & 64 & 218 & 100 \\
\hline Gratis & $(70,6 \%)$ & $(29,4 \%)$ & & \\
Membayar Sebagian & 15 & 14 & 29 & 100 \\
& $(51,7 \%)$ & $(48,3 \%)$ & & \\
Membayar Penuh & 143 & 131 & 274 & 100 \\
& $(52,2 \%)$ & $(47,8 \%)$ & & \\
\hline Total & 312 & 209 & 521 & \\
\hline
\end{tabular}

Sumber:Data Primer 2013

Berdasarkan tabel 4 tabulasi silang antara cara atau alat memperoleh kontrasepsi yang digunakan dengan kepemilikan kartu jaminan kesehatan adalah pada responden yang membayar penuh dan memiliki kartu jaminan kesehatan sejumlah 143 responden $(52,2 \%)$.

Tabel 5.Distribusi Frekuensi Alasan Responden Memilih KB Mandiri di Kota Yogyakarta Tahun 2013

\begin{tabular}{lcc}
\hline \multicolumn{1}{c}{ Alasan KB Mandiri } & Frekuensi & \% \\
\hline $\begin{array}{l}\text { Tidak mempunyai kartu jaminan } \\
\text { kesehatan }\end{array}$ & 44 & 16,1 \\
Tidak yakin terhadap pelayanan KB & 11 & 4,0 \\
pemerintah & 128 & 46,7 \\
Faktor ekonomi yang mendukung & 91 & 33,2 \\
\hline Lainya & $274^{*}$ & 100,0 \\
\hline Jumlah & & \\
\hline
\end{tabular}

Sumber: Data Primer 2013.

* Jumlah Responden KB secara mandiri.

Berdasarkan tabel 5 menunjukan bahwa alasan responden memilih KB secara mandiri paling banyak karena faktor ekonomi yang mendukung sejumlah 128 responden $(46,7 \%)$ sedangkan yang paling sedikit alasaan responden memilih KB secara mandiri karena tidak yakin dengan pelayanan pemerintah sebanyak 11 responden $(4.0 \%)$.

\section{Pembahasan}

Kemandirian KB di Kota Yogyakarta dijelaskan pada tabel 2 bahwa sebagian besar responden akseptor KB aktif memperoleh alat atau cara dengan membayar penuh yaitu sebanyak 274 (52,6\%). Usia sangat mempengaruhi tindakan dalam kemandirian $\mathrm{KB}$, karena semakin cukup usia responden akan lebih matang dalam berfikir dan menentukan pemilihan alat kontrasepsi dan kemandirian dalam ber KB. Semakin tinggi pendidikan responden prosentase memperoleh alat atau obat secara membayar penuh semakin tinggi sedangkan semakin rendah pendidikan responden prosentase memperoleh alat atau obat secara gratis semakin tinggi.

Berdasarkan tabel 4 sebagian besar responden memiliki kartu jaminan kesehatan namun responden cenderung memilih KB dengan cara membayar penuh, sedangkan alasan responden membayar penuh karena faktor ekonomi. Faktor ekonomi mempengaruhi responden dalam kemandirian KB karena dengan ekonomi yang baik dapat mempengaruhi responden memilh pelayanan KB dengan membayar penuh walaupun harus mengeluarkan biaya.

Dapat disimpulkan bahwa responden dalam memperoleh alat atau obat pada saat pelayanan KB secara membayar penuh salah satunya karena faktor ekonomi dan kepemilikan kartu jaminan kesehatan tidak mempengaruhi kemandirian KB. 
Hal ini sesuai dengan penelitian Simanjutak (2012) yang menyatakan bahwa fakor ekonomi seseorang berhubungan kuat dengan permintaan pelayanan kesehatan ${ }^{4}$.

Berdasarkan Tabel 5 menunjukkan bahwa alasan responden memilih KB secara mandiri dikarenakan tidak mempunyai kartu jaminan kesehatan, tidak yakin dengan pelayanan KB pemerintah, faktor ekonomi yang mendukung dan lainya lainya ini menjelaskan tentang alasan responden KB mandiri contohnya alasan responden karena waktu pelayanan KB pemerintah yang ditentukan jam pelayanannya, jarak pelayanan KB mandiri lebih dekat atau jarak pelayanan KB atau responden dapat kapan saja mendapatkan pelayanan $\mathrm{KB}$ asalkan sesuai dengan jadwal responden dalam ber KB.

Mayoritas responden tidak bekerja (Ibu Rumah Tingga) memilih KB mandiri dengan alasan karena faktor ekonomi. Meskipun Responden sebagian besar tidak bekerja (Ibu Rumah Tangga) diduga karena dari faktor suami yang bekerja sehingga dapat memenuhi kebutuhan responden pelayanan KB. Hal ini menunjukan bahwa KB adalah kebutuhan primer keluarga.

Hal ini sesuai dengan penelitian Simanjutak (2012) yang menyatakan bahwa fakor ekonomi seseorang berhubungan kuat dengan permintaan pelayanan kesehatan ${ }^{4}$.

\section{Simpulan dan Saran}

\section{Simpulan}

Berdasarkan hasil penelitian mengenai gambaran kemandirian KB pada pasangan usia subur di kota Yogyakarta tahun 2013 telah dilaksanakan dapat disimpulkan Cara akseptor KB aktif dalam cara memperoleh alat atau obat pada saat pelayanan KB sebagian besar adalah dengan cara membayar penuh sebanyak $52,6 \%$, Kepemilikan kartu jamianan kesehatan pada akseptor KB sebagian besar memiliki kartu jaminan kesehatan sebanyak 59,9\%, Alasan pembayaran alat atau obat pada saat pelayanan KB paling banyak responden menjawab untuk obat atau cara kontrasepsi sebanyak $70,3 \%$, Alasaan responden memilih KB secara mandiri sebagian besar karena faktor ekonomi yang mendukung sebanyak $46,7 \%$.

\section{Saran}

Saran dalam penelitian ini adalah Perlu melakukan sosialisasi KB Mandiri kepada responden yang berpendidikan rendah, umur yang masih muda, agar tercapai tujuan KB Mandiri, Dapat memberikan masukan sebagai bahan dan informasi bagi pelaksanaan program KB dalam merancang program KB.

\section{Daftar Pustaka}

1. Artanty, Wenny Djaswadi Dasuki dan Nawi Ng. 2010. PotensiAskes Yang dimiliki Rumah Tangga Terhadap Pemanfaatan aktual Pelayanan Kontrasepsi. 1 (26) : 47-52 : Berita Kedokteran Masyarakat.

2. Loemintoe, Loesye. 2011. Faktor-faktor yang berhubungan dengan pemilihan jenis alat kontrasepsi pada akseptor KB di puskesmas Pakualaman Yogyakarta. KTI : Sekolah Tinggi IImu Kesehatan Alma Ata

3. BKKBN. 2012. Data laporan Bulanan Kantor KB Kota Yogyakarta. Yogyakarta: BKKBN.

4. BKKBN, 2012. Profil Hasil Pendataan Keluarga Tahun 2011. Jakarta: BKKBN.

5. Simanjuntak, Sry Indah Rahayu. 2012. Hubungan Sosial Ekonomi dan Karakteristik Akseptor KB dengan Tingkat Kemandirian Peserta KB Baru di Kelurahan Sunggal Kelurahan Sunggal Kecamatan Medan Kota Medan Tahun 2012. 1 (1) 1-7 : Gizi, Kesehatan Reproduksi dan Epidemiologi.

6. Dinkes Kota Yogyakarta. 2013. Brosure Jaminan Kesehatan Daerah Kota Yogyakarta. Yogyakarta : Dinas Kesehatan Kota Yogyakarta

7. Fatima, Desta. 2012. Perbandiangan Kepuasan Antar Pasien Askes dan Pasien Jamkesmas di Poliklinik Penyakit dalam RSUD Dr.Kariadi Semarang. KTI : Universitas Diponegoro.

8. Handayani, S. 2010. Pelayanan Keluarga Berencana. Yogyakarta: Pustaka Rihama.

9. Hartanto. 2004. KB Keluarga Berencana dan Kontrasepsi. Jakarta: Pustaka Sinar Harapan.

10. Julianto, Arief Purnomo. 2007. Hubungan Pola Asuh Orang Tua dengan Tingkat Kemandirian Anak Usia Sekolah Di SDN Panjang Wetan 01 Pekalongan. 2 (2) : 1-6 : Pena Medika Jurnal Kesehatan.

11. Kaswian, Dede lan. 2002. Hubungan Antara Sosial Sosial Ekonomi dan Kualitas Pelayanan Kontrasepsi dengan Kemandirian Ber-KB di Desa Gawangan Kecamatan Colomadu Kabupaten Karanganyar Surakarta Tahun 2002. Skripsi : Unversitas Diponegoro.

12. Machfoedz, Ircham . 2010. Metode Penelitian Bidang Kesehatan, Keperawatan, Kebidanan, Kedokteran. Yogyakarta : Fitramaya.

13. Maryani.2008. Pelayanan Keluarga Berencana \& Pelayanan Kontrasepsi. Jakarta: Trans Info Media. 
14. Notoatmodjo. 2010. Metodelogi Penelitian Kesehatan.Jakarta : PT Rineka Cipta.

15. Pujihastuty Resty Endah dan Winarni. 2011 . Pola Pembiayaan Pelayana Kontrasepsi di 6 (Enam) Provinsi di Indonesia dalam Rangka Evaluasi Kebijakan Alat dan Obat Kontrasepsi Gratis. Jakarta Pusat : BKKBN.
16. Sihombing, Estica Tiurmauli Kristiana. 2012. Pengaruh Jaminan Kesehatan Masyarakat Pelayanan Pertolongan Persalinan Terhadap Keikutsertaan Keluarga Berencana. Pekalongan. $\mathrm{KTI}$ : Universitas Diponegoro.

17. Sugiyono.2009. Metode Penelitian Kuantitatif Kualitatif dan R\&D. Bandung : CV.Alfa Beta. 